
\title{
Open Open Patients' silence towards the healthcare system after ethical transgressions by staff: associations with patient characteristics in a cross-sectional study among Swedish female patients
}

\section{A Jelmer Brüggemann, Katarina Swahnberg}

To cite: Brüggemann AJ, Swahnberg K. Patients' silence towards the healthcare system after ethical transgressions by staff: associations with patient characteristics in a cross-sectional study among Swedish female patients. BMJ Open 2012;2:e001562. doi:10.1136/bmjopen-2012001562

- Prepublication history for this paper is available online. To view these files please visit the journal online (http://dx.doi.org/10.1136/ bmjopen-2012-001562)

Received 25 May 2012 Accepted 16 October 2012

This final article is available for use under the terms of the Creative Commons Attribution Non-Commercial 2.0 Licence; see http://bmjopen.bmj.com
Gender and Medicine, Department of Clinical and Experimental Medicine, Linköping University, Linköping, Sweden

\section{Correspondence to} Dr A Jelmer Brüggemann; jelmer.bruggemann@liu.se

\section{ABSTRACT}

Objectives: To identify which patient characteristics are associated with silence towards the healthcare system after experiences of abusive or ethically wrongful transgressive behaviour by healthcare staff. Design: Cross-sectional questionnaire study using the Transgressions of Ethical Principles in Health Care Questionnaire.

Setting: A women's clinic in the south of Sweden. Participants: Selection criteria were: consecutive female patients coming for an outpatient appointment, $\geq 18$-year-old, with the ability to speak and understand the Swedish language, and a known address.

Questionnaires were answered by 534 women $(60 \%)$ who had visited the clinic, of which 293 were included in the present study sample.

Primary outcome measure: How many times the respondent remained silent towards the healthcare system relative to the number of times the respondent spoke up.

Results: Associations were found between patients' silence towards the healthcare system and young age as well as lower self-rated knowledge of patient rights. Both variables showed independent effects on patients' silence in a multivariate model. No associations were found with social status, country of birth, health or other abuse.

Conclusions: The results offer opportunities for designing interventions to stimulate patients to speak up and open up the clinical climate, for which the responsibility lies in the hands of staff; but more research is needed.

\section{INTRODUCTION}

A recent volume of BMJ Quality and Safety focused on patients' 'bad experiences in the hospital'. ${ }^{1}$ These experiences, illustrated in two patient stories, highlighted inhumane aspects of care, beyond or despite technically correct treatment. ${ }^{2}{ }^{3}$ Similar experiences have also been labelled abuse in healthcare

\section{ARTICLE SUMMARY}

Article focus

- Many patients remain silent towards the healthcare system after experiencing abusive or wrongful ethical transgressions by staff, in this article it is examined which patient characteristics associate with whether or not to speak up about such events.

\section{Key messages}

- It was shown that remaining silent towards the healthcare system was negatively associated with the knowledge that patients have of their rights and with the patients' ages.

- Associations between remaining silent towards the healthcare system and patients' social status, country of birth, their backgrounds of abuse or their health status could not be confirmed.

- The results could inform patient education interventions that stimulate and enable patients to speak up.

Strengths and limitations of this study

- This study is the first to examine which patient characteristics associate with remaining silent to the healthcare system after experiencing abusive or wrongful ethical transgressions.

- Due to measurement problems, including small group sizes, not all hypotheses could be tested with equal statistical rigidity.

(AHC) and high numbers have been reported. AHC has been described as patients' subjective experiences characterised by a lack of care, which implies suffering and the feeling of losing one's value as a human being. ${ }^{4}$ These events are most often of unintentional nature. Studies in the Nordic countries showed that lifetime prevalence of AHC ranged between $13 \%$ and $28 \%$ in female patients. ${ }^{5}$ Current suffering was reported by $8-20 \%$ of all women. ${ }^{5}$ The approximate prevalence of AHC among Swedish men was 
$7 \%$, and $4 \%$ of the male sample reported current suffering. ${ }^{6}$ Qualitative studies have shown that female patients who experienced AHC felt powerless and ignored, and experienced carelessness and non-empathy, resulting in the core category 'being nullified'? A related study among male patients showed that men had similar experiences, but instead of turning their emotions inwards, they wanted to express their emotions and felt hindered in doing so, resulting in the core category 'being mentally pinioned'. 8

It can be assumed that face-to-face incidents of violence never exist in isolation. Johan Galtung's theory of violence views these incidents of direct violence as part of a complex environment, consisting of possible violent structures and cultural norms and taboos, which feed and legitimise direct violence. ${ }^{9-12}$ If healthcare providers want to understand and change these structures and cultures it is important to structurally include patients in healthcare processes, as some have suggested for the prevention of medical errors and quality improvement. ${ }^{13} 14$ According to sociologist Anthony Giddens, structures are the rules and routines that at the same time enable and limit individuals' behaviour. ${ }^{15}$ Each time individuals act according to existing routines, these routines are reproduced and confirmed. These routines, however, can be changed through different feedback mechanisms inherent to the process of reproducing structures. A first step in that direction could be to examine and consider patients' feedback to the healthcare system.

One branch of research that aims to include patients' evaluations in healthcare processes are studies of formal patient complaints. ${ }^{16} 17$ However, it has been shown that formal complaints are strongly biased and only represent specific patients and events, for example those events that patients feel competent to complain about, such as a hospital's 'hotel' services. ${ }^{18}$ In a study on the expression of dissatisfaction, a British research group found that only a small number of incidents were filed as formal complaints; the majority of expressions was done verbally, and the patient did not label this as 'complaining'. ${ }^{18}$ This suggests it could be more accurate and preferable to also concentrate on other forms of feedback, such as directly speaking to staff: so-called informal complaints. ${ }^{19}$

In a recent study based on the Transgressions of Ethical Principles in Health Care Questionnaire (TEP), AHC was operationalised as patients' experiences of staff's ethical transgressions and it was examined to what extent patients speak up or remain silent towards the healthcare system after experiencing such events. ${ }^{20}$ In the study $(\mathrm{N}=530)$ it was found that the vast majority of female patients had experienced such events, and many patients experienced these events as abusive and wrongful. More than two-thirds of these patients had remained silent towards the healthcare system about at least one experienced event. For some transgressions, more than $80 \%$ of the patients had kept silent, despite feeling abused by the event or judging it as wrongful. Patients' silence about abusive events is alarming as it is not only directly harmful to patients, but a lack of patient feedback also hampers structural improvements.

Patients might have certain characteristics that affect whether or not they speak up about abuse they may have experienced within the healthcare system. The overarching aim of this study, also based on TEP, was to gain knowledge about these characteristics, which could contribute to more effective clinical interventions that ultimately decrease the prevalence of AHC, for which healthcare staff is responsible.

\section{Hypotheses}

We hypothesised that patients' silence towards the healthcare system was related to their older age, lowersocial status and foreign birth (outside of Sweden). Each of these characteristics is shown to be associated with low levels of assertiveness in medical settings, and with lower rates of informal complaining. ${ }^{19}{ }^{21-23}$ It was also hypothesised that patients with a history of other kinds of abuse were more likely to remain silent towards the healthcare, as they may have felt more guilt and shame caused by fear of negative reactions and blame by others. ${ }^{12}$ Furthermore, we hypothesised that the occurrence of patients remaining silent towards the healthcare system could be related to their poor health and little knowledge of patient rights.

\section{METHOD}

\section{Subjects and procedure}

Over the period between September 2009 and May 2010, TEP was sent to 890 female patients. ${ }^{20}$ These patients were recruited at a women's clinic at a county hospital in the south of Sweden. This clinic was chosen because of an ongoing collaboration between the clinic and our research group, and because of the clinic's great variety of patients, including those coming for routine screening procedures. Also, female patients have reported AHC to a much higher degree than men, which was another reason to explore these questions in a female sample. The sample was selected according to the following criteria: participants must (1) be a consecutive female patient coming for an outpatient appointment, (2) be $\geq 18$-year-old, (3) speak and understand the Swedish language and (4) have a known address. Patients first received an information letter from a secretary at the clinic and had the option to decline participation. Patients who did not decline participation received a second information letter, TEP and a prepaid return envelope at home. Two reminders were sent out with 2-week intervals. The study was approved by the regional ethical review board (reg.no. M116-09).

\section{Measurements}

TEP describes 23 events that operationalise transgressions of ethical principles in healthcare. Five categories of transgressed ethical principles were identified, and 
the events were distributed over these categories as follows: autonomy 5; justice 2; physical non-maleficence 4 ; integrity 4 and sexual non-maleficence 8 (box 1).

Patients report whether they experienced such events, whether they experienced them as abusive, whether they judged the event as wrongful, and whether they acted upon it or spoke up (table 1). 'Remaining silent' was defined as patients refraining from giving direct feedback to the healthcare system, despite experiencing an event as abusive or wrongful.

The face validity of this 'silence construction', based on a qualitative judgement, was considered to be good. ${ }^{20}$ Patients' reports of abusive transgressions in TEP also showed satisfactory convergent validity with patients' reports to the AHC questions from the validated Norvold Abuse Questionnaire (NorAQ; validated in a Swedish female sample) $;{ }^{24}$ sensitivity and specificity were found to be $82 \%$ and $80 \%$, respectively.

The way 'remaining silent' was operationalised in TEP has a starting point in James Rest's four component model of moral behaviour. ${ }^{25}$ This model identifies four components that are necessary for moral action to come about: moral sensitivity, moral judgement, moral motivation and moral character. In TEP, these components were transformed into questions concerning patients' experiences of and actions after staff's transgressions. More detailed information about TEP and its underlying theoretical assumptions have been described elsewhere. ${ }^{20}$

TEP also includes questions about sociodemography, history of abuse, self-rated health and knowledge of patient rights.

Questions about sociodemography included 'year-ofbirth' (age recoded into two categories: $<30, \geq 30$ years; fit line in scatterplot with age and the dependent variable showed a clear cut-off at age 30), 'education' (recoded into three categories: $<10,10-12,>12$ years), 'country of birth' (recoded into four categories: Sweden, other Nordic country, other European country, outside Europe), 'occupation' (recoded into two categories: (self-employed or other, which included: studying, unemployed, parental leave, sick leave, retired, social welfare and homemaker), 'income' (original alternatives: <7000, 7-14900, 15-24 900, 25-34 900, 35-44 900, 45-54 900, 55-65 000, $>65000$ SEK) and 'subjective social status', based on the idea of how one sees oneself in relation to others in society, considering money, job and education. ${ }^{26}$ The MacArthur Scale of Subjective Social Status (a 10-point ladder rank) is a well-established instrument of which we

Box 1 Operationalisations of ethical principles in the Transgressions of Ethical Principles in Health Care Questionnaire

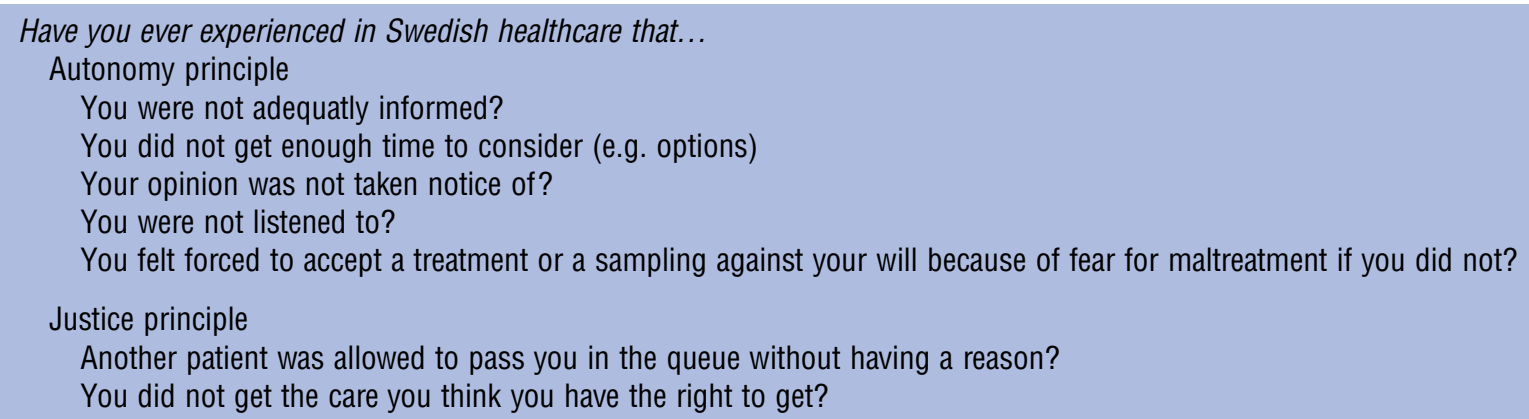

Have you ever experienced in Swedish healthcare that staff...

Physical non-maleficence principle

Held you firmly against your will?

Performed an examination/treatment in a too rough way?

Continued an examination in spite of your protests?

Hit you or threatened to hit you?

Integrity principle

Exposed you to mockery?

Humiliated you?

Made you feel forgotten or neglected?

Violated his/her professional secrecy concerning you?

Sexual non-maleficence principle

Watched you undress or dress instead of offering you to do it in private?

Commented or criticised with a sexual undertone, your underwear or your body?

Flirted or talked to you in a seductive way?

Told you about his/her own sexual preferences, problems or fantasies?

Performed an examination in a way that you perceived as having an undertone of sex?

Touched in a sexual way your breasts, external genitals or other parts of your body?

Encourages you to masturbate or made you watch him/her masturbate?

Wished to start a sexual relationship with you? 
Table 1 Transgression and silence questions in the Transgressions of Ethical Principles in Health Care Questionnaire

\begin{tabular}{|c|c|c|c|c|}
\hline $\begin{array}{l}\text { Have you ever } \\
\text { experienced in Swedish } \\
\text { healthcare that... }\end{array}$ & & $\begin{array}{l}\text { (A) Did you perceive } \\
\text { what happened as } \\
\text { abusive? }\end{array}$ & $\begin{array}{l}\text { (B) Did you judge } \\
\text { what happened as } \\
\text { wrongful? }\end{array}$ & $\begin{array}{l}\text { (C) Have you talked about what happened } \\
\text { with the healthcare staff, complained or } \\
\text { made clear in any other way that you } \\
\text { experienced what happened in this way? }\end{array}$ \\
\hline $\begin{array}{l}\text { Example cases of } \\
\text { transgression }\end{array}$ & Yes/No & Yes/No & Yes/No & Yes/No \\
\hline
\end{tabular}

used a Swedish translation. ${ }^{27}$ This measurement was expected to better explain variance in silence than the objective measurements of 'income', 'education' and 'occupation'. Objective measurements are useful for the guidance of effective interventions, since they are more concrete than 'subjective social status', ${ }^{27}$ and they were therefore included as well.

The patients' history of other kinds of abuse, that is, emotional, physical and sexual, was measured using the abuse questions from NorAQ. ${ }^{28}$ The questionnaire identifies different levels of abuse: mild, moderate and severe. The abuse questions in NorAQ have shown good reliability and validity, with an interview as the gold standard in a sample of Swedish women $(n=64) \cdot{ }^{24} \mathrm{~A}$ full version of the abuse questions in NorAQ can be found in Swahnberg et $a l^{5}{ }^{5}$ Respondents who answered yes to at least one of the three questions for each type of abuse were regarded as having experienced that type of abuse, regardless of severity. The exception to this was 'mild physical abuse', which was shown to be rather unspecific, ${ }^{24}$ and which was included in the category 'no lifetime physical abuse'. 'Self-rated health' was measured on a seven-point Likert item (1=very bad, 7=very good). Lastly, knowledge of patient rights was operationalised as self-rated knowledge of these rights, asking respondents to rate their knowledge level on an 11-point item (original coding: $0=$ none, $10=$ to a high degree) .

As it has been suggested that non-response can be seen as an extrapolation of late response, we included the variable 'days to respond', based on 30 days to 12 months. $^{29}$ Any association between this variable and an outcome variable could point at a possible response bias in the data set.

\section{Study design}

From the abovementioned silence operationalisation in TEP, we developed a dependent variable that indicates how many times the respondent remained silent relative to the number of times the respondent spoke up, expressed as a percentage of the total number of opportunities to remain silent and speak up (continuous variable, 0-100, where $100 \%$ indicated 'remained silent after all events' and $0 \%$ meant 'acted after all events'). As this variable showed a U-distribution, which was hard to model as a dependent variable, it was chosen to trichotomise the variable (ordinal: 1=0\%, 2=1-99\%, 3=100\%; figure 1). Associations with silence were first tested univariately, using Cramer's V (nominal by ordinal) and Kruskal's $\gamma$ (ordinal by ordinal and interval by ordinal). Accordingly, all variables that tested significantly were included in an ordinal logistic regression model (through a generalised linear model) testing for the main effect of these variables on the ordinal dependent variable. 'Knowledge of patient rights' was entered as a covariate, assuming a continuous scale. Missing values due to item non-response were excluded from the analyses. Statistical analyses were performed using the IBM Statistical Package of the Social Sciences V.19.0. Test results with a $\mathrm{p}$ value of $<0.05$ were considered significant.

\section{RESULTS}

Sixty per cent $(534 / 891)$ of female patients answered and returned TEP and 530 were included in our final dataset, as four respondents were excluded (one male patient, and three patients because of invalid answers or more than half of the answers missing). Fifty-five per cent of the sample $(293 / 530)$ reported at least one transgression that they judged abusive or wrongful and were included in the present study sample (see figure 2). Background data are shown in table 2 and more detailed information about the total sample is described elsewhere. ${ }^{20}$ For all variables shown in table 2, the number of participants with missing values ranged between 2 and 11 .

Univariate analyses showed no associations between 'remaining silent' and the patients' social status, country

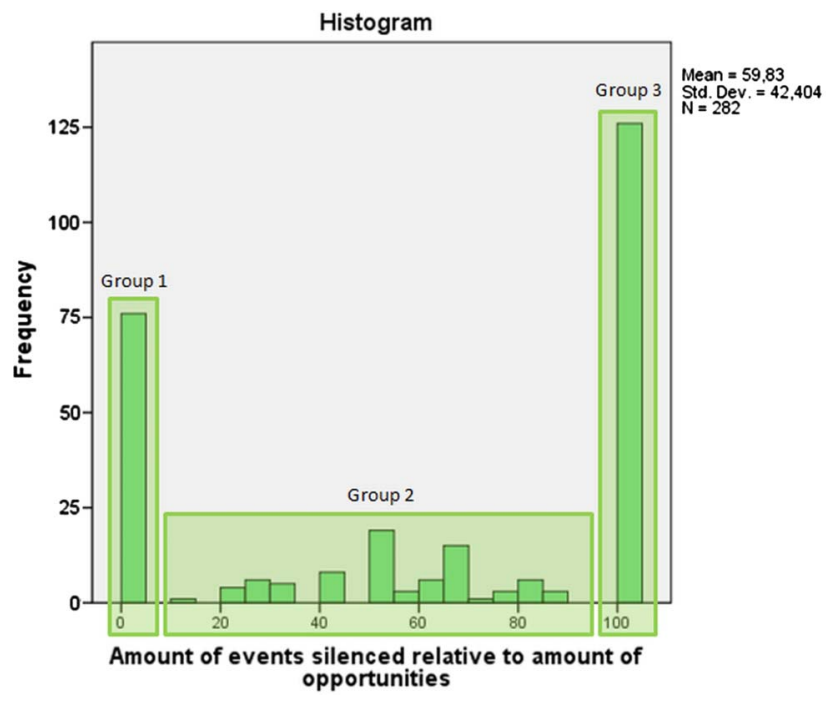

Figure 1 Histogram of the continuous variable "remaining silent" and the three groups derived from this variable. 


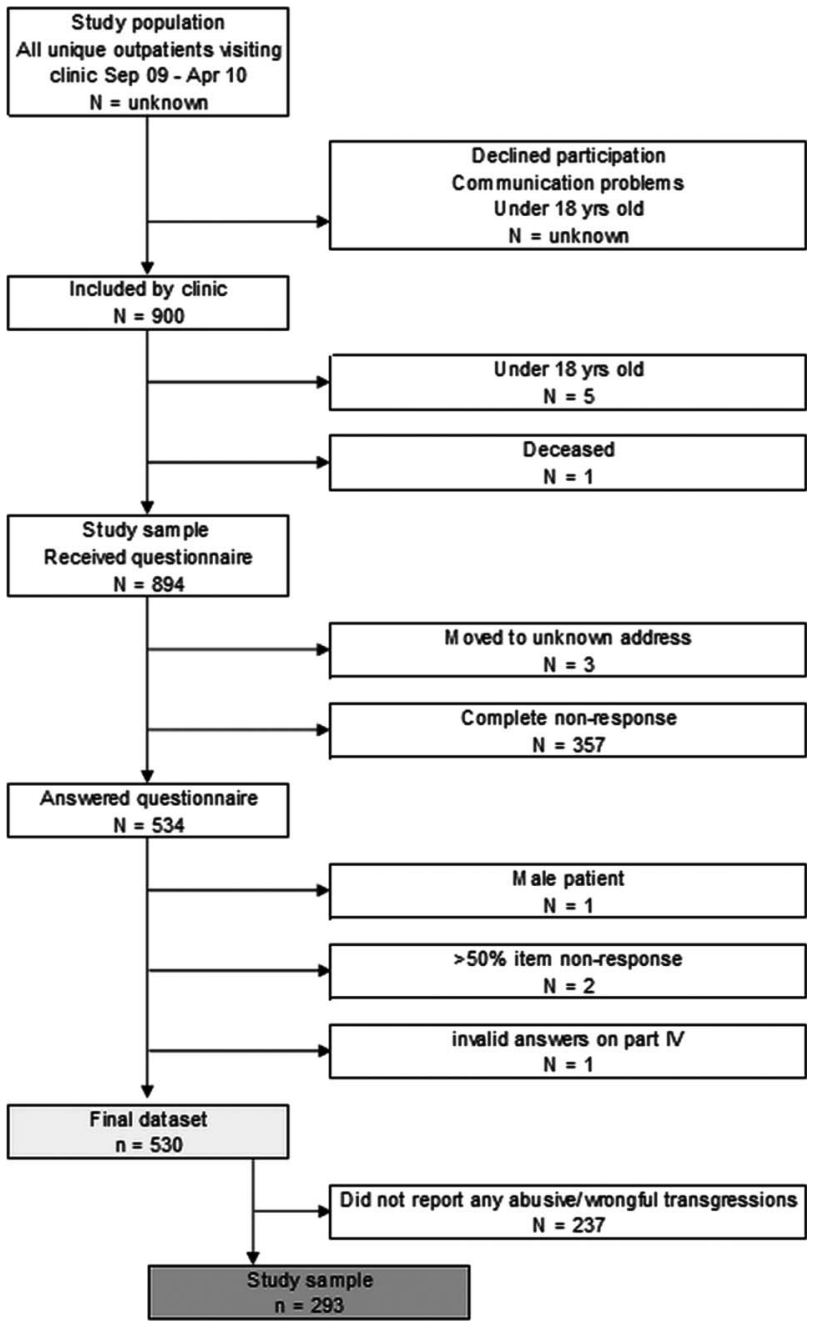

Figure 2 Flow diagram showing the numbers of individuals at each stage of study.

of birth, their background of abuse or their health status. Associations were found with 'age' and 'knowledge of patient rights' (table 2). Considering 'age', the youngest age group reported a higher rate of silence towards the healthcare system (figure 3). 'Knowledge of patient rights' was negatively correlated with 'remaining silent', implying that a higher reported knowledge was associated with a lower rate of silence towards the healthcare system (figure 4).

The regression model that included both of these variables showed that both 'age' and 'knowledge of patient rights' had an effect on 'remaining silent' (table 3). 'Age' and 'knowledge of patient rights' were not associated with each other.

This result did not change when only looking at abusive or wrongful events, although the association between 'remaining silent' after abusive events and 'knowledge of patient rights' was only significant if 'remaining silent' was used as a dichotomous variable $(1=0 \%, 2=1-100 \%)$ in a binary regression model (data not shown).
Further examination showed that 'knowledge of patient rights' did not correlate with the number of events experienced, nor with the number of events that were perceived as abusive or wrongful (table 4).

\section{DISCUSSION}

Despite extensive research on formal complaints and a growing interest in patient behaviour concerning informal complaints, ${ }^{18} 19$ little is known about patient behaviour after abusive or ethically wrongful events in healthcare. In the present study, we investigated which patient characteristics are associated with remaining silent after such events. It was shown that this silence was negatively associated with the knowledge that patients have of their rights and with the patients' ages. However, we could not confirm associations with patients' social status, country of birth, their backgrounds of abuse or their health status.

A negative association was found between the knowledge that patients have of their rights and patients remaining silent towards the healthcare system. It was surprising to see that knowledge of patient rights was not associated with the number of experienced events, nor with the number of events perceived as abusive or wrongful. One explanation for this could be that patients' 'common sense' beliefs highly converge with what is included in patient right and ethical documents, and that more knowledge about these rights not necessarily leads to more experiences of transgressions. Many of the ethical documents and guidelines are based on Beauchamp and Childress' principles of biomedical ethics, which in its turn is based on 'commonmorality'. ${ }^{30}$ For that reason, knowledge of patient rights would not change patients' judgements of the events described in TEP. However, when it comes to acting after an abusive or wrongful situation, this knowledge could increase a patient's moral motivation or moral identity, and help her to feel legitimised to act when she knows ethical or legal rules have been transgressed, although no conclusions about causality can be made based on the current material. The fact that this patients' knowledge was self-reported in this study may suggest the importance of patients believing that they know their rights, rather than patients actually knowing their rights.

In spite of the small-scale and cross-sectional character of the current study, this result could suggest two entrances for future interventions. The first entrance could be to increase the actual knowledge patients have of their rights, for example by making information about rights more accessible. The second could be to strengthen the belief that patients know what is right and wrong when a staff member transgresses ethical principles. The latter may be strongly related to patients' self-efficacy, or the fact that patients believe in their capacities; which, according to Bandura, ${ }^{31}$ may also affect their level of motivation for a certain behavioural path. Besides trying to increase the knowledge patients have 
Table 2 Univariate analyses of predictor variables with the ordinal dependent variable (expressed as the number of times remained silent as a percentage of the total number of opportunities)

\begin{tabular}{|c|c|c|c|c|}
\hline \multirow[b]{2}{*}{$n=293^{*}$} & \multicolumn{3}{|l|}{ Remained silent } & \multirow[b]{2}{*}{ p Value } \\
\hline & $\overline{0 \%}$ & $1-99 \%$ & $100 \%$ & \\
\hline \multicolumn{4}{|l|}{ Age (range $19-85$, mean $42.5 \pm 14.0$ )† } & 0.03 \\
\hline$<30$ & $8(14.0)$ & $17(29.8)$ & $32(56.1)$ & \\
\hline$\geq 30$ & $68(29.1)$ & $74(31.6)$ & $92(39.3)$ & \\
\hline \multicolumn{4}{|l|}{ Education (years) $\ddagger$} & 0.84 \\
\hline$<10$ & 9 (24.3) & $13(35.1)$ & $15(40.5)$ & \\
\hline $10-12$ & $30(24.8)$ & $37(30.6)$ & $54(44.6)$ & \\
\hline$>12$ & $36(27.1)$ & $40(30.1)$ & $57(42.9)$ & \\
\hline \multicolumn{4}{|l|}{ Country of birth $\dagger$} & 0.91 \\
\hline Sweden & $63(24.4)$ & $82(31.8)$ & $113(43.8)$ & \\
\hline Other Nordic country & $1(20.0)$ & $2(40.0)$ & $2(40.0)$ & \\
\hline Other European country & $4(40.0)$ & $3(30.0$ & $3(30.0)$ & \\
\hline Outside Europe & 5 (33.3) & $4(26.7)$ & $6(40.0)$ & \\
\hline \multicolumn{4}{|l|}{ Occupation (latest 12 months)† } & 0.93 \\
\hline (Self) employed & $61(26.6)$ & $69(30.1)$ & $99(43.2)$ & \\
\hline Other & $14(24.1)$ & $18(31.0)$ & $26(44.8)$ & \\
\hline \multicolumn{4}{|l|}{ Any lifetime emotional abuse§ł } & 0.30 \\
\hline No & $55(29.6)$ & $51(27.4)$ & $80(43.0)$ & \\
\hline Yes & $19(18.3)$ & $40(38.5)$ & $45(43.3)$ & \\
\hline \multicolumn{4}{|l|}{ Any lifetime physical abuse§ł } & 0.33 \\
\hline No (including mild abuse) & $57(26.9)$ & 57 (26.9) & $98(46.2)$ & \\
\hline Yes & $18(22.8)$ & $34(43.0)$ & $27(34.2)$ & \\
\hline \multicolumn{4}{|l|}{ Any lifetime sexual abuse§ł } & 0.08 \\
\hline No & $66(29.9)$ & $61(27.6)$ & $94(42.5)$ & \\
\hline \multirow[t]{2}{*}{ Yes } & 9 (12.9) & $29(41.4)$ & $32(45.7)$ & \\
\hline & Median (range) & & & \\
\hline \multicolumn{4}{|l|}{ Self-rated health $\ddagger$} & 0.13 \\
\hline Range 1-7 ( 7 being very good) & $5(1-7)$ & & & \\
\hline \multicolumn{4}{|l|}{ Household income (SEK/month before taxes) $\ddagger$} & 0.09 \\
\hline Range $<7000 \longrightarrow 65000$ & $35-44900(<7000->65000)$ & & & \\
\hline \multicolumn{4}{|l|}{ Subjective social status $\ddagger$} & 0.17 \\
\hline Range $1-10$ (10 being the highest) & $6(1-10)$ & & & \\
\hline \multicolumn{4}{|l|}{ Knowledge of patient rights $\ddagger$} & $<0.01$ \\
\hline Range $0-10(0=$ none, $10=$ to a high degree $)$ & $4(0-10)$ & & & \\
\hline \multicolumn{4}{|l|}{ Days to respond $\ddagger$} & 0.49 \\
\hline Based on 12 months to 30 days & $18(0-273)$ & & & \\
\hline \multicolumn{5}{|l|}{$\begin{array}{l}\text { *deviations in percentages exist due to item non-response. } \\
\text { ttested with Cramer's V. } \\
\text { ftested with Kruskal's } \gamma \text {. }\end{array}$} \\
\hline
\end{tabular}

of their rights through persuasive communication, Bandura $^{32}$ defined three other sources for increasing self-efficacy. The first source is 'performance accomplishments', which are experiences of successful outcomes after performing certain tasks. The second source is 'vicarious experiences', which have a starting point in the identification with a role model. Third, we see a 'physiological state', which concerns information from a patient's own bodily state. Future interventions could focus on strengthening any of these sources, but as Bandura pointed out, mere persuasive communication is a very weak source for increasing self-efficacy and could therefore better be combined with any of the other three sources.
More importantly, we believe that any patient education intervention should not only focus on behavioural change in patients; the intervention should be sensitively embedded in clinical practice, including the engagement of staff. ${ }^{33}$ In the end, staff is responsible for not acting in an abusive way towards patients.

Patients' silence towards the healthcare system was also associated with age, but contrary to our expectations, the youngest age group tended to remain silent slightly more often. It should be noted, however, that this group was compared with a group of patients over 30 years of age with relatively few respondents over the age of 65 . A sample including more patients $>65$ years of age could give contrary results. We could also discuss the initial 


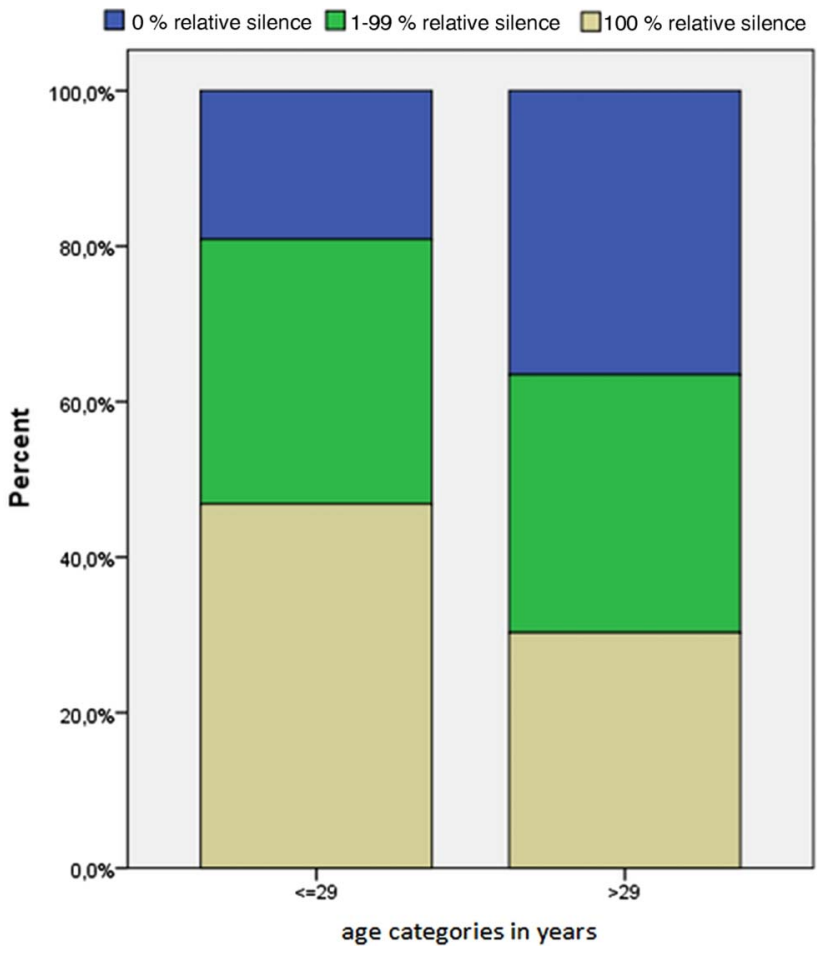

Figure 3 Distribution of patients' relative silence after abusive and/or wrongful ethical transgressions within two age categories.

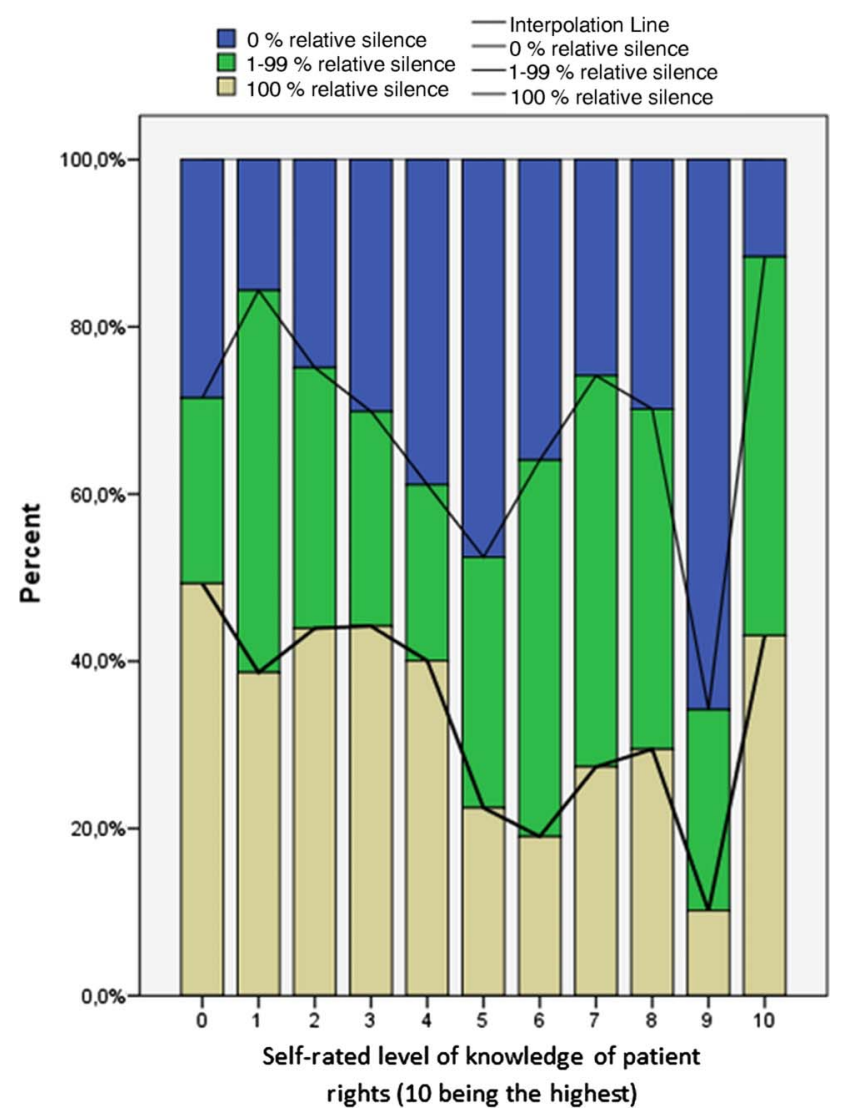

Figure 4 Distributions of patients' relative silence after abusive and/or wrongful ethical transgressions within patients' self-rated level of knowledge of their rights. assumption on which this hypothesis is based, namely that patients speaking up after and abusive event is convergent with their assertiveness. Galtung' ${ }^{10}$ structuralist theory of violence would suggest that which patient characteristics are associated with silence depends on existing structures, rather than patients' assertiveness. For example, in a study on cancer communication patterns, it was suggested that certain patient characteristics, such as race, strongly influenced the physicians' communication style, which in its turn could affect patient behaviour. $^{21}$ The fact that younger patients remain silent to a higher degree could, according to this reasoning, depend on how well healthcare structures and staff are prepared to motivate younger patients to speak up. Following this theoretical reasoning, such a structural bias or prejudice could jeopardise the treatment of younger patients and hinder these patients from becoming involved in feedback processes.

Some of our hypotheses could not be confirmed. One general explanation for this is that the area has hardly been studied, and that our hypotheses were based on knowledge from related fields. Also, some methodological limitations may have affected these results. First, considering country of birth, the small group sizes posed a problem, as in total only $10 \%$ of all patients were born outside Sweden. Larger groups could have shown different results, more in line with our hypothesis. Second, the self-rated health item we used concerned the last 12 months, while our silence operationalisation covered lifetime experiences. It would have been more accurate to estimate patients' health at the time of the event. Questions about other kinds of abuse also covered lifetime experiences and hence could have happened after transgressions in healthcare. Besides these methodological limitations, other explanations for the fact that we found only two associations with patient characteristics could be that we missed relevant variables, or that remaining silent is, for the most part, dependent on the structural conditions present in the actual healthcare situation. It may be a sign that structural conditions, such as healthcare norms and taboos, are powerful enough to outweigh the bulk of differences between individual patients. For example, differences in patients' social status can still imply differences in assertiveness but they are irrelevant if all patients feel equally powerless to act after abusive events.

As we know that male and female patients experience AHC in different ways, ${ }^{28}{ }^{30}$ it should be taken into account that the current study only included female patients. A qualitative study on how Latino American women dealt with dissatisfying healthcare experiences found that these women mostly avoided confrontation. ${ }^{34}$ Instead of confronting a physician, the women chose indirect strategies such as switching healthcare providers. In that study it is suggested that these strategies may reflect traditional gender norms, where women tend to avoid confrontation with authority figures. ${ }^{34}$ In TEP, such actions are not included in the silence 
Table 3 Ordinal Logistic Regression (through a generalised linear model) with study variables and ordinal dependent variable. $\beta$-Coefficients $(B)$ and $\mathrm{Cl}$ for regressions with patients' silence towards the healthcare system after experiencing staff's abusive or wrongful transgressions

\begin{tabular}{|c|c|c|c|c|c|c|}
\hline \multirow[b]{2}{*}{$\mathrm{n}=275^{\star}$} & & \multirow[b]{2}{*}{ B } & \multirow[b]{2}{*}{ SE B } & \multicolumn{2}{|c|}{ 95\% Wald Cl } & \multirow[b]{2}{*}{ p Value } \\
\hline & & & & Lower & Upper & \\
\hline \multirow[t]{2}{*}{ Threshold } & Remained silent $0 \%$ & -2.07 & 0.34 & -2.74 & -1.40 & $<0.01$ \\
\hline & Remained silent $1-99 \%$ & -0.82 & 0.32 & -1.45 & -0.18 & 0.01 \\
\hline \multicolumn{7}{|c|}{ 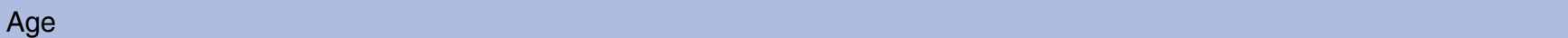 } \\
\hline$<30$ & & 0 & & & & \\
\hline$>30$ & & -0.71 & 0.29 & -1.29 & -0.14 & 0.02 \\
\hline Knowledge of patient rights & & -0.11 & 0.04 & -0.19 & -0.03 & $<0.01$ \\
\hline
\end{tabular}

Table 4 Correlation coefficients (Spearman's $\rho$ ) for 'knowledge of patient rights' and four study variables (on a continuous scale)

\begin{tabular}{|c|c|c|c|c|}
\hline & $n=288 \dagger$ & $n=288$ & $n=288$ & $\mathrm{n}=277$ \\
\hline & $\begin{array}{l}\text { Number of } \\
\text { experienced events }\end{array}$ & $\begin{array}{l}\text { Number of events } \\
\text { perceived as abusive }\end{array}$ & $\begin{array}{l}\text { Number of events } \\
\text { judged as wrongful }\end{array}$ & $\begin{array}{l}\text { Remained silent relative } \\
\text { to opportunities }\end{array}$ \\
\hline $\begin{array}{l}\text { Knowledge of } \\
\text { patient rights }\end{array}$ & $<0.01$ & -0.20 & $<0.01$ & $-0.19^{\star}$ \\
\hline
\end{tabular}

operationalisation as they were not expected to function as direct feedback to the healthcare system. ${ }^{20}$ This means that we only capture a part of women's strategies, and also that if men apply more direct strategies, we would expect to find less silence in TEP in male patients. On the other hand, a qualitative study with male patients about their experiences of AHC showed that they felt 'mentally pinioned', which included their frustration after the powerlessness of not being able to act according to their interests. Hence, it could very well be that male patients also feel forced to avoid conflicts within a healthcare setting, deviating from a traditional male norm. Male patients' silence could be a subject for future studies.

\section{CONCLUSION}

Remaining silent after experiencing healthcare staff's abusive or wrongful transgressions was negatively associated with the knowledge that patients have of their rights and with their ages. Both these variables could offer opportunities for designing patient education interventions that stimulate patients to speak up and open up the clinical climate, but more research is needed. It should be emphasised that it is not the responsibility of patients to speak up to staff to decrease the prevalence of AHC; staff carries the responsibility for this.

Acknowledgements The NorVold Abuse Questionnaire (NorAQ) was developed by NorVold, a research network established in 1997 to explore the prevalence of violence against women and its effects on women's health. The
NorVold research network was supported by grants from the Nordic Council of Ministers. Principal investigators: Barbro Wijma, Berit Schei. Coordinator: Katarina Swahnberg. Local investigators: Denmark: Katrine Sidenius, Malene Hilden, Finland: Erja Halmesmäki, Ulla Pikkarinen, Iceland: Tora Steingrimsdottir, Norway: Berit Schei, Hildegunn Stoum-Hinsverk, Kristin Offerdal, Sweden: Barbro Wijma, Katarina Swahnberg. We are grateful to Isa McKechnie for language editing this article.

Contributors AJB studied conception/design, data collection and analysis, drafting of manuscript, critical revisions for important intellectual content. KS studied conception/design, data collection/analysis, critical revisions for important intellectual content and supervision.

Funding This study was supported by the Swedish Research Council (no. 2009-2380).

Competing interests None.

Ethics approval The regional ethical review board in Linköping, Sweden.

Provenance and peer review Not commissioned; externally peer reviewed. Data sharing statement Extra data are available by emailing AJB ( jelmer. bruggemann@liu.se).

\section{REFERENCES}

1. Levinson $\mathrm{W}$, Shojania KG. Bad experiences in the hospital: the stories keep coming. BMJ Qual Saf 2011;20:911-13.

2. Villette M. For want of a four-cent pull chain. BMJ Qual Saf 2011;20:986-90.

3. McCullough M. An ethicist's journey as a patient: are we sliding down the slippery slope to sloppy healthcare? BMJ Qual Saf 2011;20:983-5.

4. Brüggemann AJ, Wijma B, Swahnberg K. Abuse in health care: a concept analysis. Scand J Caring Sci 2012;26:123-32.

5. Swahnberg K, Schei B, Hilden M, et al. Patients' experiences of abuse in health care: a Nordic study on prevalence and associated factors in gynecological patients. Acta Obstet Gynecol Scand 2007;86:349-56. 
6. Swahnberg K, Hearn J, Wijma B. Prevalence of perceived experiences of emotional, physical, sexual, and health care abuse in a Swedish male patient sample. Violence Vict 2009;24:265-79.

7. Swahnberg K, Thapar-Bjorkert S, Bertero C. Nullified: women's perceptions of being abused in health care. J Psychosom Obstet Gynaecol 2007;28:161-7.

8. Swahnberg K, Wijma B, Hearn J, et al. Mentally pinioned: men's perceptions of being abused in health care. Int J Mens Health 2009;8:60-71.

9. Galtung J. Violence, peace and peace research. $J$ Peace Res 1969;6:167-91.

10. Galtung J. Cultural violence. J Peace Res 1990;27:291-305.

11. Wijma B, Gustafsson LE, Thapar-Bjorkert S, et al. What is an error? J Psychosom Obstet Gynaecol 2005;26:233-5.

12. Wijma B, Thapar-Bjorkert S, Hammarström NC, et al. Cycles of abuse nurtured by concealment: a clinical report. $J$ Psychosom Obstet Gynaecol 2007;28:155-60.

13. Cleland JGF, Ekman I. Enlisting the help of the largest health care workforce-patients. JAMA 304:1383-4.

14. Unruh KT, Pratt W. Patients as actors: the patient's role in detecting, preventing, and recovering from medical errors. Int $J$ Med Inform 2007;76:S236-44.

15. Giddens A. The constitution of society: outline of the theory of structuration. Berkeley, CA: University of California Press, 1984.

16. Hsieh SY. The use of patient complaints to drive quality improvement: an exploratory study in Taiwan. Health Serv Manage Res 2010;23:5-11.

17. Jangland E, Gunningberg L, Carlsson M. Patients' and relatives' complaints about encounters and communication in health care: evidence for quality improvement. Patient Educ Couns 2009;75:199-204.

18. Mulcahy L, Tritter JQ. Pathways, pyramids and icebergs? Mapping the links between dissatisfaction and complaints. Sociol Health IIIn 1998;20:825-47.

19. Gal I, Doron I. Informal complaints on health services: hidden patterns, hidden potentials. Int J Qual Health Care 2007;19:158-63.

20. Brüggemann AJ, Wijma B, Swahnberg K. Patients' silence following healthcare staff's ethical transgressions. Nurs Ethics 2012;19:750-63.
21. Siminoff LA, Graham GC, Gordon NH. Cancer communication patterns and the influence of patient characteristics: disparities in information-giving and affective behaviors. Patient Educ Couns 2006:62:355-60.

22. Lee KB, Vaishnavi SN, Lau SK, et al. Cultural competency in medical education: demographic differences associated with medical student communication styles and clinical clerkship feedback. $J$ Natl Med Assoc 2009;101:116-26.

23. Andersen MR, Guthrie KA, Urban N. Assertiveness with physicians: does it predict mammography use? Women Health 2004;39:1-11.

24. Swahnberg K, Wijma B. The NorVold Abuse Questionnaire (NorAQ): validation of new measures of emotional, physical, and sexual abuse, and abuse in the health care system among women. Eur $J$ Public Health 2003:13:361-6.

25. Rest JR. Background: theory and research. In: Rest J, Narváez D, eds. Moral development in the professions: psychology and applied ethics. Hillsdale, New Jersey: Lawrence Erlbaum Associates, 1994:1-26.

26. Adler NE, Epel ES, Castellazzo G, et al. Relationship of subjective and objective social status with psychological and physiological functioning: preliminary data in healthy white women. Health Psychol 2000;19:586-92.

27. Lundberg J. Social status: a state of mind? Linköping, Sweden: Linköping University Medical Dissertation no. 1083, 2008.

28. Wijma B, Schei B, Swahnberg K. Nor AQ. The NorVold Abuse Questionnaire. Linköping: Division of Gender and Medicine, Faculty of Health Sciences, Linköping University, 2004.

29. Lindner JR, Murphy TH, Briers GE. Handling nonresponse in social science research. J Agr Educ 2001;42:43-53.

30. Beauchamp TL, Childress JF. Principles of biomedical ethics. New York: Oxford University Press, 2001.

31. Bandura A. Human agency in social cognitive theory. Am Psychol 1989;44:1175-84

32. Bandura A. Social foundations of thought and action: a social cognitive theory. EnglewoodCliffs, NJ: Prentice-Hall, 1986.

33. Schwappach DLB. Engaging patients as vigilant partners in safety: a systematic review. Med Care Res Rev 2009;67:119-48.

34. Weitzman PF, Chang G, Reynoso H. Middle-aged and older Latino American women in the patient-doctor interaction. $J$ Cross Cult Gerontol 2004;19:221-39. 